\title{
Out of the ivory tower: the impact of wider social contact on the values, religious beliefs and identities of Chinese postgraduate students in the UK
}

Article

Accepted Version

Li, D. (2012) Out of the ivory tower: the impact of wider social contact on the values, religious beliefs and identities of Chinese postgraduate students in the UK. Race, Ethnicity and Education, 12 (2). pp. 241-258. ISSN 1470-109X doi: https://doi.org/10.1080/13613324.2011.585339 Available at https://centaur.reading.ac.uk/20710/

It is advisable to refer to the publisher's version if you intend to cite from the work. See Guidance on citing.

To link to this article DOI: http://dx.doi.org/10.1080/13613324.2011.585339

Publisher: Taylor \& Francis

All outputs in CentAUR are protected by Intellectual Property Rights law, including copyright law. Copyright and IPR is retained by the creators or other copyright holders. Terms and conditions for use of this material are defined in the End User Agreement. 


\section{CentAUR}

Central Archive at the University of Reading

Reading's research outputs online 


\section{Out of the Ivory Tower: The impact of wider social contact on the values, religious beliefs and identities of Chinese postgraduate students in the UK}

Daguo Li ${ }^{*}$

National Centre for Language and Literacy, University of Reading, Reading, UK

Detailed address:

National Centre for Language and Literacy, University of Reading, Bulmershe Court, Earley, Reading, RG6 1HY

Tel: 01183785916

Biographical notes:

I am Lecturer of Education and Deputy Director of the National Centre for Language and Literacy, University of Reading. I teach on residential courses for Chinese secondary teachers of English and MA in English and Language in Education. I am currently jointly supervising two PhD students in the areas of teacher development and international education. I am also Convenor of the Second Language Research Group at the Institute of Education of the University.

"Email: d.li@reading.ac.uk 


\begin{abstract}
This paper explores the impact of wider social contact on the experience of Chinese postgraduate students of adaptation to life in the UK. Focus group and individual interviews were conducted with a group of 11 Chinese students on an MA programme at a university in Southern England and individual interviews with three representatives of a local volunteer group (LVG) offering support to the Chinese students. Although it was perceived that the students' support needs were not adequately met by the University, the additional support offered outside the University was unanimously valued and considered as enriching their cultural and linguistic experiences and meeting their expectations. However, frequent social contact with the LVG, whose members were mostly Christians, also had an impact on their values, religious beliefs and identities. In a discussion framed within the sociological perspective of proselytization or religious conversion and the broad framework of international education and globalization, the different responses to this contact are described in terms of believers, doubters, empathisers and commentators. Implications are considered for universities, people involved in providing social support for international students, and sponsors of international students.
\end{abstract}

Keywords: Chinese students; adaptation; identities; religious beliefs; proselytization 


\section{Introduction}

International migration represents "the human face of globalization" (Keeley 2009, 1). Many migrants of Chinese origin, in modern history, particularly from the mid- $19^{\text {th }}$ to the mid-20 th $^{\text {ch }}$ century, were "forced migrants" (Keeley 2009, 26) or "unwilling migrants" (Yang 1998, 249) - people fleeing wars, natural disasters, social turmoil, or political campaigns and seeking refuge in a foreign land. Nowadays, however, with the modernization programme and rapid economic and social developments, Chinese people tend to migrate voluntarily, often as short-term migrants to advance their education or future careers. English-speaking Western countries, such as the USA, UK, Canada, Australia, and New Zealand, are particularly attractive destinations. For example, Chinese students represent the largest as well as the fastest growing international student population in the UK. In 2007, the number of Chinese students in the UK was over 60,000 , with a rate of growth of $11 \%$ over the previous year (The British Council 2008). The attractiveness of the UK as a study abroad destination for Chinese students, despite its relatively high level of tuition fees, owes much to its linguistic and cultural capital. Linguistically, English is the global language of communication (Crystal 2003; Graddol 1997) and the UK enjoys the status of being the country of origin of English. For many Chinese students, the UK is the ideal place to experience and improve their English in addition to their academic ambitions. Culturally, the rich literary heritage of the UK is readily recognized by the educated Chinese, reinforcing a literary or even romantic image of the UK as a land of roses and the land of Jane Austen, full of gentlemen and ladies (Philo n.d.).

Because of the particular significance of Chinese students to UK higher education in the global education market, efforts have been made to better understand this group 
of international students. These include their educational experience (e.g. UKCOSA 2004), their socio-psychological and cognitive characteristics (Li 2001, 2006, 2007), and their academic and linguistic needs (Coverdale-Jones and Rastall 2006; Edwards and An 2006; Edwards, An, and Li 2007). One issue often highlighted in these investigations is the need for more social contact and integration with British students and staff and the local communities (Edwards et al. 2007; Li 2006; UKCOSA 2004). These investigations are largely motivated, however, by pragmatic or policy concerns (Carénas 2006). For example, it is hoped that an understanding of student experience may help improve levels of support, often with the aim of enhancing the competitiveness of UK higher education in the international education market.

Recent research on the adaptation of international students in general, and of Chinese students in particular, focuses on the issue of identities (Back 2001; Carénas 2006; Chowdhurry 2009; Ding 2008, 2009; Dolby 2005; Hsieh 2006; Patron 2005). Carénas (2006), for example, explores the identities of 15 mature postgraduate students (both Masters' and Doctorate) at the University of Reading in England, with a multi-disciplinary theoretical framework (incorporating sociology, linguistics, intercultural studies and anthropology) and a qualitative approach. Her analogy of international student identities as Russian Dolls emphasizes the complexity and multilayered nature of this phenomenon. One identity may become more salient at a given moment in a social space (both academic and non-academic). Drawing on her own experience and insight as an international student, Carénas argues that international students constantly reconstruct these identities as part of the adaptive process of sojourners (short-term immigrants) in a globalised world. 
Ding (2008) adopts a critical ethnographic stance in her study of four mature Chinese students on Masters' programmes in London. She presents a narrative account of the psychological bewilderment and emotional difficulties the students have experienced in a new cultural environment. Her observation of the perceived lack of understanding and empathy, by the host institution and society, of these students' cultural values, history and society, is an attempt to represent the voice of otherwise invisible Chinese students in their encounters with the West. Ultimately it is perceived to be a struggle for resolution of the dilemma and ambiguity experienced around the changing self as international students in a post-modern, post-colonial metropolis in a globalised world. Ding argues for greater willingness by Westerners to understand the perspectives and needs of people from non-Western countries rather than the impostion on others of their own perceptions. This line of inquiry tends to draw on the broad theoretical framework of globalisation and post-modern and postcolonial perspectives, as discussed, for example, in Giddens (1991), Castells (1997) and Mendieta (2003). Within these theoretical perspectives, identities are seen as being constructed and reconstructed in an increasingly globalised world.

Another line of inquiry closely related to the issue of identity of Chinese international students is the sociological research on proselytization - the conversion of Chinese students to Christianity by American Evangelical churches (Abel 2006; Hall 2006; Wang and Yang 2006; Yang 1998; Yang and Tamney 2006; Zhang 2006). These researchers examine the high rate of conversion (about one in three) of Chinese students in the US. Various factors, including macro-, meso- and micro-level social factors are proposed to account for this phenomenon of mass conversion (Abel 2006; Yang and Tamney 2006). Macro-social and cultural factors include: the religious void 
in China - lack of strong religious beliefs characteristic of many other nationalities; social problems in China, e.g. dissatisfaction with materialism, and the valuing of certain Chinese cultural features that are believed to be consonant with Christian principles. Meso-contextual or organisational factors refer to "the religious organisational ecology" (Wang and Yang 2006, 180), i.e. local religious groups and institutions. Micro-level social processes are the "sociological interaction rituals", e.g. favours, helpfulness - "favour-fishing rituals" (Abel 2006, 176) - offered by religious organisations. This sociological framework explains the social processes implicated in the conversion of Chinese students to Evangelical Protestantism in the United States.

In the UK, informal observations show that spiritual and religious beliefs seem to have become an important aspect of life for an increasing number of Chinese students. However, there is a lack of research on the phenomenon. Existing research in the UK context rarely ventures beyond the more immediate academic and linguistic needs of Chinese students. The present research aims to broaden the scope of inquiry by looking at the social, cultural and spiritual aspects of the experience of Chinese students in the UK as well as their linguistics needs, in the context of their social and cultural contact outside the university - the "Ivory Tower". Specifically, it seeks to answer the following questions:

1. What are the support needs of Chinese students, as perceived by themselves and others?

2. What are the students' perceptions of the support provided?

3. How does the support received impact on the values and beliefs of the students in their adaptation process? 


\section{The study}

The present study focuses on the cohort of 11 Chinese students on an MA programme at a university in Southern England (hereinafter referred to as "the University") during the academic year 2006-7. They came to study at the University as a partnership arrangement between the University and a local Chinese education authority - an increasingly important form of collaboration between British universities and their Chinese counterparts. The students in question were all secondary teachers of English before they were enrolled and all had to fulfil the English language requirement, which was an average score of 7.0 on IELTS. There were 3 men and 8 women, and their ages range from late $20 \mathrm{~s}$ to $30 \mathrm{~s}$. Views were also sought from three representatives - one was an organiser and the other two were active members - of a local volunteer group (LVG) involved in supporting the students both socially and culturally. To ensure anonymity of all the participants, pseudonyms will be adopted in this report.

Data were collected with the following methods at several stages. A focus group discussion was conducted with the 11 students in the Spring Term 2007 (about three months after their arrival in the UK). Individual interviews with the three representatives of the LVG were carried out towards the end of the Spring Term. In addition, individual interviews with the students were conducted towards the end of their course. The focus group discussions and individual interviews with the $11 \mathrm{MA}$ students were conducted in Chinese and all the other interviews were conducted in English. All the data were transcribed and prepared for analysis with ATLAS.ti 5.0, a specialist software package for the analysis of qualitative data. Systematic coding was 
carried out and common themes were identified. The main findings are presented below.

\section{Support needs perceived by the Chinese students and the LVG}

In both focus group discussions and individual interviews, the students reported that they expected to improve their linguistic skills and cultural understanding from the start of their course. The following comments were typical:

My biggest expectation is to improve my speaking in English. As for the academic degree, we're all qualified [teachers] to some extent. So the main purpose is to improve my spoken English. (Hualing, Focus Group)

At the start, I was very ambitious, ... thinking, ah, great, my speaking skills can be improved in leaps and bounds and I will be completely transformed, as would be the expectation of my school ... (Xiaoli, Interview)

My first objective was to get to know the customs and people in the UK and how their language is used - how people use language in their daily life. Secondly, I wanted to know British people's life, particularly what the life of the local people is like - their food, clothing, and various other aspects ... (Feng, Interview)

Sometimes, this need seemed to be influenced by the perceived high expectations of the students as language teachers on the part of their schools and colleagues back home; on other occasions, it was attributed to their perceived difficulty with communication in English:

At home, a teacher is always judged by his or her spoken English when evaluating his or her basic skills. It is the most important criterion. (Yuhua, Focus Group) 
They couldn't understand my speaking. That made me feel very upset. (Jing, Focus Group)

For one thing, it has to do with my linguistic competence: I could not fully understand the tutors and I could not express myself [freely]. (Yuhua, Interview)

The University offered two main kinds of support in relation to these needs. The students lived in a student Hall of Residence, where they were mixed with other international students and potentially had the opportunity to communicate in English. They could also benefit from the additional support with their writing and pronunciation in the form of in-sessional English language support for international students funded by the School where they were studying for their Masters'. However, they felt isolated because they perceived that opportunities for social interaction with other international students and, particularly local people, were limited. The fact that they were all Chinese was not very helpful either. They expressed their disappointment and even frustration in the following terms:

... we thought we might be able to have more social interaction with the Westerners, and we could improve our speaking fast. But in fact the Hall where we live is rather isolated from the outside. There is not much chance to communicate with others. ... When I speak more with native speakers, I feel my speaking improves a lot. But this kind of chance is rare. ... Now one third of the time is over, but we don't feel much improvement. (Haiyan, Focus Group)

We expect to improve our speaking a lot. But in fact we live in a group, and we cannot get out of this circle, so we didn't make full use of the chance to improve our spoken English. The progress in speaking is not ideal. (Yuhua, Focus Group) 
This feeling of isolation and lack of social interaction with local people mirrors the experience of Chinese students in earlier surveys (e.g. UKCOSA, 2004).

The LVG, in contrast, seemed attuned to the needs of these Chinese students. It had been involved in voluntarily supporting international students from the University for many years. It consisted of British returnees from overseas, who were mainly Christians. Their initial motivation to start the group was to help international students and, in so doing, to project a good image of British people. One representative of the LVG, Paul, commented that he had special feelings towards Chinese people and Chinese students because of his son's connection with China and his previous experience of travelling and teaching in China. However, he believed their more deepseated intrinsic motivation to help the students originated from their Christian faith, although they did not want to publicise themselves as a religious group:

The majority are [Christians], so part of their motivation is simply their belief or faith. We are told to welcome strangers or foreigners. It is very clear in the Bible, if you want to honour or please God, you will actually respond this way, so for some of us, we may feel this is our Godgiven mission.

It is not just someone says this is a good idea. Generally they find in them, in your hearts a love or joy - and I have to say this is how I treat my kids. ... It takes faith; without it we probably wouldn't be running this program. But having said that, as you can see in our program, we want to welcome everybody to [this town] from all faiths and those from no faith, so we don't advertise ourselves as a Christian organization or whatever because it is not appropriate, not relevant.

Clearly they find their efforts to help others, including the Chinese students, fulfilling 
and rewarding:

Yes, I think we get a sense of personal fulfillment for contributing to other people's lives. And I feel it's worthwhile. (Richard, representative of LVG)

We feel very rewarded if we can help somebody, because we understand a bit what it is to be a stranger in a foreign land and need help with the language. We learned the Philipino language from an old lady who was very patient. (Elizabeth, representative of LVG)

Based on their own experiences of working and living in other countries, they believed they had a good understanding of the potential problems faced by international students, e.g. practical problems of settling in and loneliness and isolation as their course progressed. To alleviate these problems, they aimed to provide international students with continuing support, something which they perceived as often lacking in the normal university provision:

... the University provides, when the new students come at the beginning of the Autumn Term, there is a big welcome: "You are welcome! We are so happy that you have come." That's it, finished, and nothing else happens. Because the Overseas Students Department [International Office] just wants to recruit more students for the next year, so they forget about where they would go. This is one big deficiency of the university welcoming program, it doesn't continue. You have a big welcome, a big dinner, then nothing good continues. (Richard, representative of LVG)

Members of the LVG believed they had identified a clear gap in the normal services provided by the University (e.g. The International Office, The Counseling Service, The Health Centre, and The Students' Union): 
the international [postgraduate] students seem to have problems and needs which are not met through bodies like Students' Union, Counseling Service, like Health Center and so on. They are not the same as undergraduates. ... There are various reasons. One reason is that many students are older than the average undergraduates; secondly, they pay a lot more, so they have different social needs than the UK students. The University at the moment is not doing much except those officially provided by the International Office and the Counseling Service, and the Students' Union has recognized over the years what we local volunteers are doing is very useful and helpful, therefore they give us publicity ... last year we got free accommodation ... for the events on campus, so we are able to use University facilities, free of charge. (Paul, representative of LVG)

It is also interesting to note that the volunteers regarded the Students' Union as essentially an undergraduate organization, which could not reach out to international students, particularly mature postgraduate students:

I have an eighteen-year-old daughter I know the current students, it is normal that they behave in a particular way, so their activities are sort of involved in parties and alcohol and just not particularly caters to some of the students. There are many coming from different economic and cultural backgrounds. They are not interested in music and dancing. That is the struggle the Students Union has: how to incorporate with the different groups of students? The Students Union is primarily the undergraduate organization because the majority are undergraduate students; and so it is quite difficult for the international students to have much impact on the Students Union or make the Union work for them, provide something for them. So that's why, it is really a gap, it is a kind of we feeling it, we try a little bit of it, we try to recognize the result, that is to say, let's do something really enjoyable. (Paul, representative of LVG)

Volunteers also recognized the need for individualized pastoral care under their wing which it believed could not have been achieved by the Student Services offered 
by the University:

Sometime the University has passed people on to us, the Counseling Department. A student has come from a different country, maybe an older student. Sometimes they find it difficult in halls, if the hall is noisy. They may get homesick, and not coping well with studies. ... sometimes it's ladies who are lonely, so we try to get that person in a home environment to have a nice relaxing time and it does help. The university can't provide that help, the normal Counseling Service. It is not just the case of talking with that person, you have to put them into a different environment where they can literally feel relaxed. And that helps better to cope with the loneliness or homesickness and they find they do better in their studies. (Richard, representative of $\mathrm{LVG}$ )

The LVG volunteers decided to organize a range of activities to support international students, for example, Friday evening entertainment and cultural programmes (Barn Dance, British Festivals or Chinese New Year, etc.), hospitality scheme, and weekend and holiday trips. The hospitality scheme was offered especially over Christmas, commonly recognized as a very lonely and difficult period of time for international students. Weekend excursions were normally day trips to surrounding historical, cultural or tourist attractions and the occasional longer trips were organized for vacations, for example Easter. Members of the LVG often accompanied the trip acting both as organizers and tour guides. It was a good international mix. The 11 Chinese students were regular participants and, because of the size of the group, were often the majority in a particular gathering and very distinctive.

\section{Students' perception of the support provided}

Overall, the students felt that this wider social support provided a good platform for them to make contact with the local people and to be exposed to British culture, which 
would otherwise be unavailable, as summarised by the leader of the Chinese student group ${ }^{1}$ :

When international students like us travel abroad for the first time, to a new place, with no friends, but are keen to understand the [local] culture and to make contact with the local people, there are not many opportunities. But it [the LVG] has provided an excellent platform for us. (Wenhui, Interview)

The Chinese students believed that the benefits of this participation were multiple. They welcomed the practical and financial benefits, for example, the low cost one-day excursions and the trips to Scotland and Wales, which not only saved them money but also time in terms of organisation. They felt these activities created opportunities for socialisation which not only provided recreation and relaxation but, more importantly, also helped relieve isolation - a problem they reported in their earlier focus group discussions, which is also widely reported among international students. All 11 students agreed on the linguistic benefits. The opportunities for social interaction often one-to-one - in English with the local people and other international students helped to improve their language skills. They also agreed on the broad cultural benefits in terms of enriching their cultural experience and broadening their perspectives. Therefore, the perceived needs of the group, i.e. to have contact with local people in real situations in order to experience the host culture and improve their linguistic skills, particularly their speaking skills, seem to have been largely met. It is also worth mentioning that, unlike many other Chinese students studying abroad (e.g. Li 2001), these students felt they did not have much difficulty coping with the daily communicative demands of life in the UK. As English language teachers, they were motivated to develop their English language skills further while also gaining exposure 
to British culture. There was unanimous agreement among the group on the great hospitality and kindness shown to them by the LVG. Similar gratitude was acknowledged by past participants of LVG from other countries (e.g. Fuata'I 2000).

Impact of wider social support on the students'values, religious beliefs and identities

The students' extensive contact with the LVG, however, had a strong impact on the values, religious beliefs and the identities of the former. Participants can be divided into four main groups - believers, doubters, empathisers and commentators.

\section{The believers}

By actively participating in the events and meetings organised by the LVG, two students, Min and Hui, developed a strong affiliation with the LVG. They were particularly moved by the perceived selfless support and care provided by its members, which they felt to be in sharp contrast to the widespread utilitarian and materialist pursuits of modern day China (see also Wang and Yang 2006). They were eventually converted to Christianity, the religion of the majority of the LVG, towards the end of the academic year. Min and Hui could thus be called the believers. They embraced Christianity and felt this newly-found faith elevated them, making them feel a kind of freedom they had never experienced before. For Min, this development was in marked contrast to her childhood experience and feelings of being constrained by what she believed to be the superstitions associated with her grandmother's belief in Buddhism (e.g. not a good omen to travel on a particular day). She felt Christianity does not hold back people in that way but rather offers them freedom. Interestingly though, she also readily attributed recent happenings to her in the UK (e.g. ease of 
finding alternative accommodation when her family came to visit from China) to God's answer to her call, a response which some might interpret as a form of superstition similar to those she had associated with Buddhism. Therefore, it could be argued that her decision to embrace this new opportunity for change was only partially rational. Hui was more reluctant to discuss the issue of his religious conversion openly in the interview, even though it was already public knowledge within his group. His wish for privacy had to be respected.

\section{The doubter}

One student, Yuhua, expressed utter disbelief and unhappiness at these students' conversion to Christianity. This student could thus be called the doubter. Yuhua admitted experiencing great culture shock because of the issue of religion. She was clearly agonizing over what had happened and the confusion and anxiety negatively impacted on her:

But to me, in the course of mixing with them [members of the LVG], I felt the pressure, because I was aware some of them are missionaries and their job is to spread God's love to more people. But for myself, I have accepted your favour but I cannot live up to your expectations. So later on I felt the pressure. Others in our group might have felt differently, but this is how I felt. I was faced with the dilemma and was confused for two weeks and it even affected my studies and daily life.

The following account gives a clear indication of the extreme pressure Yuhua experienced at meetings with the group, leading to her eventually to decide to avoid going to such gatherings: 
[I was] under a lot of pressure. At the start we were singing [hymns]. That's fine. Then they [members of the LVG] started saying prayers. Saying prayers was also all right, as we simply listened. Then they handed you bread and wine and emphasized repeatedly that if you ate the bread and drank the wine, you would become immortal and God's love would be bestowed on you. But once you eat the bread and drink the wine, it means you have accepted Him. Then they said the bread is God's flesh and the wine is God's blood. When you drink the wine, it means... I have been to such occasions twice. When they were passed on to me, I [immediately] passed them on to others. Then somebody sitting behind me was staring at me, I felt very embarrassed. When they saw it, they said to me, "If you are sitting there finding it difficult to drink it, you can tell me and I will help you to accept God". I found it extremely embarrassing, so later I decided to avoid [going to such gatherings].

\section{The conflicts between the believers and the doubter}

Tension seemed to build between the believers and the doubter on the issue of faith and religious conversion and reached a climax in a clash between one of the believers (Min) and the doubter (Yuhua) where both parties were upset and stormed out. The argument concerned whether adopting this so-called "Western" Christian belief amounts to rejecting or betraying their Chinese culture - Chinese traditional values and beliefs and their own more "native" religious belief (e.g. Buddhism). The doubter, Yuhua, felt strongly about the potential negative impact on their families back home: "How could we then face our families (as we are devout Buddhist families) when we return to China? Primarily because we do not want to upset our families". She considered her fellow students' transformation unacceptable. She lamented the fact that, when the group arrived, Christians were in the minority (two of them were from Christian families in China), but one year on, when they were about to return to China, Christians would be the majority. 
Min, however, felt the adoption of a new faith was her own choice and nobody should blame her. Therefore, she felt particularly hurt when she was accused of giving up her Chinese culture and she defended herself thus:

\footnotetext{
I don't think accepting Christianity means giving up Chinese culture. ... Actually I myself am quite traditional, and I am from a quite traditional family. But in religion, based on my current superficial understanding, as I am studying the Bible - I feel it is a wonderful book. ... I have been studying the Bible after joining their Bible Studies. ... I feel there are many things in it worth learning, for example, truth, kindness, and beauty. Aren't they also what Chinese culture aspires to? Moreover, religion is only a small part of culture. As for the influence of Western religion on Chinese culture, it depends on how you look at it. There may be good or bad influences, right?
}

Many of the Chinese converts to Christianity in the United States reported in Wang and Yang (2006) had the same belief, i.e. becoming a Christian did not necessarily mean one had to completely reject Chinese culture. Min also argued that the accusation by her fellow student (Yuhua) amounts to narrow nationalism. She nevertheless agreed that her quarrel with Yuhua essentially represented both cultural and ideological clashes.

\section{The empathisers}

Two in the student group (Ling and Feng) supported the doubter whilst four others (Wenhui, Xiaoli, Jing, and Haiyan) empathised with the believers. This group constituted the empathisers.

Those who empathised with the doubter expressed slight reservations and unease about the radical change in the believers. They agreed with Yuhua's concerns about 
the perceived attempt of some LVG members to convert them:

Because we are friends, occasionally they ask me whether I've had any change in my faith. But I have my own view. I feel only when you feel you yourself are not strong enough do you start to have a different faith. I feel I am still in control of myself, so I won't believe in it to that extent. This is how I understand it. So I myself do not have a particular faith. Later on when they pushed me to join the group, I no longer went to their Bible study activities ... Since we can't always control our own feelings, if I am really persuaded by them to believe in it, it may be against my original wish. So I have almost stopped going to the Bible study activities. (Ling, Interview)

Later on, I clearly felt other people, those from X Church, those staff, ... asked very aggressive questions, "Do you accept God"? I said "No". Then he asked, "Why not? If you accept God, we will be of one family, as brothers and sisters." I wondered why not avoid asking such questions. I said, “I must have my reason why I don’t believe in God. I am in my thirties. I am no longer a three-year-old". So I joked with a British friend, when he asked me why not accept God, "I am too old to believe in God". (Feng, Interview)

This comment provides support for Carénas's (2006) observation that mature students have well-established adult identities; they are therefore able to resist social forces or pressure for change.

Those who empathised with the believers expressed solidarity and understanding and argued that their decision was a matter of individual choice. One of these, Xiaoli, while agreeing that the issue of religion caused much conflict among the group, disagreed on the view of Christianity as "Western" and Buddhism as "Chinese":

There was a lot of conflict among us on this issue ... Some argued 'we are Chinese and 
Buddhism ought to be our faith, if we are to have a faith at all'. But Buddhism is not our traditional religion. It came from India, didn't it?

\section{The commentators}

The remaining two students, Hongmei and Hualing, did not seem to take sides with either the believers or the doubter and their empathisers. They tried to maintain a neutral stance and could be termed the commentators. Hongmei seemed uncertain about the issue of religious belief, though. She had to fall back on her family and seek advice from her father back in China. The conclusion she eventually drew was that such an important decision should not be rushed, at least not now when she felt she was in a vulnerable position as an international student in a foreign land and may be easily persuaded. For those who had adopted the new faith, she wondered whether their decision was partly out of a utilitarian motive, that is, adopting the faith for temporary benefits and advantage, for example, legitimate membership of the local LVG. So she posed the following question and warning: "Have you really thought it through? Don't play with God!” Hualing expressed a more critical view of the nature of their contact with the LVG. To her, the intensive experience with only one group of people or one organisation (the LVG), kind and hospitable as they were, was clearly limiting. But she was also aware of the lack of alternative opportunities for other types of contact:

The overall environment they have offered us is good ... but apart from that, we have no alternative choices. ... But if we had had other types of contact, it would have been even better. ... We could have had a better understanding of what other British are like. But so far we only know what Christians are like. As for other ordinary people, business people, for example, what the life of ordinary people is like, we have no idea. (Hualing, Interview) 
The group dynamics - individual vs. group identities

It is worth pointing out the collectivist identity of this student group. Firstly, they came as a group on a partnership scheme, with a group leader appointed by the local Chinese education authority that sponsored them. There was an obligation to conform to their own group norms of behaviour or an identity consonant with their existing cultural beliefs and values and political ideology (e.g. not to participate in religious activities during their study abroad, as instructed by their local education authority at their pre-departure briefing). This was the case particularly since they came from a society where the collectivistic ideal is upheld (Scollon and Scollon 1995). Secondly, the nature of their participation in the LVG activities could be characterised as collective. As commented by both the representatives of the LVG and the students themselves, they were often the majority of the students who attended the activities organised by the LVG and were a very distinctive group. This collective participation meant that any perceived shift in group identity by its members (e.g. as exemplified by the believers of the Christian faith and their empathisers who now became the majority of the group) could be used to constrain individuals who attempted to deviate. This helped to explain why for a period of time Yuhua, the doubter, found herself confused and agonising over her group membership, as the following reflection shows:

... because the others around you, the group, were all participating [in the LVG activities] ... If I had come on my own, I could have easily avoided participating in them. But because we came as a group, if you were the only one who were stubborn and did not want to participate, you would feel isolated. ... If I had come on my own, it [the issue of religion] might not have had the strong impact on me, but since I belonged to a group, when the majority were moving in that direction and only you yourself stayed where you were ... 
Although she eventually decided to withdraw from attending some of the religious activities, such as Bible Studies, as did her two empathisers (Ling and Feng), apparently it was not an easy decision to take.

In the students' adaptation process, there seemed a tension between individual and group identities. On the one hand, there were attempts by individuals to reshape their identities by adopting the Christian belief, as in the case of the believers Min and Hui, or to hold on to their existing identity, as in the case of the doubter, Yuhua. On the other hand, the collectivist ideal or group identity, itself going through a process of reshaping, worked to exert pressure on individuals to conform to the existing or evolving group identities.

It should be emphasised that the religious organisational ecology (see Wang and Yang 2006), as embodied in the LVG, seemed to have had a decisive influence on the reshaping of the identities of this group of students. The frequent participation in their activities and the close ties thus formed with the LVG, created the conditions for some students to convert to Christianity.

\section{Discussion and conclusion}

The needs of the Chinese students in the present study, as perceived both by themselves and by others, seemed to go beyond academic and linguistic realms. Their aspirations for more social and cultural contact did not seem to be adequately met by normal provision at the university. To fill this gap, the continuing support provided by the LVG was welcomed. By actively participating in the activities organized by the 
LVG, the students were able to have multiple benefits - linguistic, financial, social and cultural. However, the extensive social and cultural exposure to the LVG, whose members were predominantly Christians, was also shown to impact on the students' cultural values and religious beliefs and, ultimately, their individual and group identities.

The sociological perspectives on religious conversion in the United States offer useful explanations for the phenomenon. At the macro-level, rapid social, economic and cultural changes in China pose challenges, particularly in terms of people's values and beliefs. These challenges seemed to have encouraged some Chinese postgraduate students in the present study to take advantage of the "alternate meaning systems" (Yang 1998, 251) available in the present social and cultural context. At the mesolevel, although the LVG was not an openly religious organization, its members were nearly all Christians and it could thus be called a quasi-religious group. The values and beliefs thus embodied can be regarded as constituting "the religious organisational ecology" (Wang and Yang 2006, 180), an important factor in religious conversion. Perhaps even more important is the micro-level "sociological interaction rituals" or "favour-fishing rituals" (Abel 2006, 176). Events, trips and hospitality provided tangible practical benefits, making participation attractive at the same time serving as important socialisation processes, which may have contributed to the religious conversion of the two students. However, favour-fishing would suggest a pro-active approach to religious conversion by a religious organisation. On the one hand, this interpretation may seem a rather cynical view of the LVG given its articulated motives; on the other hand, data from the doubter, Yuhua, and her two sympathisers (Ling and Feng) would suggest an underlying religious motive, at least 
among some members of the LVG. Nevertheless, the conversion of the Chinese students to Christianity documented both in the US and in the present study seems to be the result of a reactive response, on the part of the students, to the opportunities and local context, i.e. "the religious organisational ecology" (Wang and Yang 2006, 180).

The sociological perspectives on this phenomenon offered in previous studies are illuminating but were focused on the converts only (e.g. Wang and Yang 2006). The present data seems to suggest a more complex picture. We see diverse reactions to the issue of religious faith, characterised by the two extremes (the believers and doubter) with the sympathisers and observers in between. The internal conflict and anxiety experienced by some of the Chinese students and the tension within the group around the issue of religious beliefs and culture represent the struggle entailed in reconstructing individual and group identities. Nevertheless, the Chinese students seem to have exhibited a considerable degree of agency (see $\mathrm{Ng} 2002$ ) by examining more deeply their own existing core cultural values and beliefs in the face of opportunities for the reconstruction of their identities. In the broad context of globalisation and international education, with increasing student mobility, the issue of identities will undoubtedly take on more significance.

While recognizing the limited scope of the present case study on the adaptive experience of a small group of Chinese students in a particular social and cultural context and the potential danger of attempting to generalize the findings to other contexts, some implications can be usefully discussed. In recent years, there has been increasing willingness on the part of western host institutions to adapt in order to 
enhance the quality of experience - academic, social and psychological - of international students (Edwards et al. 2007). However, such willingness needs to be translated into tangible help and support; this is how the work of the LVG was able to make a difference. Similarly, university student unions and organizations need to cater to the needs of both undergraduate and postgraduate students, particularly postgraduate international students.

International student support is a complex issue. For people who offer social support and pastoral care outside the academic context, awareness of the potential impact on cultural groups or individuals within those groups is extremely important. Such awareness could help to reduce or remove suspicions that they are trying to impose their own religious or ideological values and beliefs on those from different cultural backgrounds. This course of action could lead to a more pleasant and truly enriching cultural experience for all parties.

By the same token, it is important for sponsors of Chinese students, whether as parents or organizations, to recognize the cultural impact and the potential freedom of choice in terms of values and beliefs that international education can offer students.

In addition to an academic degree, Chinese students will return home with feelings of gratitude to the people with whom they have come into contact, for the hospitality they have offered and for the friendship they have established, as well as their lived cultural experience and renegotiated identities. The longer term impact of their social and cultural experience abroad on their personal and professional lives after their return could be the topic of future research. 
Notes

1. The 11 Chinese students came on a partnership arrangement between the British university and a Chinese local education authority. A leader was appointed by the latter as an organiser and representative of the group.

\section{References}

Abel, A. 2006. Favor fishing and punch-bowl Christians: Ritual and conversion in a Chinese Protestant Church. Sociology of Religion 67, no. 2: 161-178.

Back, A. 2001. Issues of identity and control for Chinese students in Australia. PhD diss., Griffith University.

Carénas, F. 2006. Exploring the impact of British higher education on the identites of international students. PhD diss., The University of Reading.

Castells, M. 1997. The Information Age: Economy, Society and Culture, Volume II: The Power of Identity. Malden, Mass.: Blackwell publishers.

Chowdhurry, M. R. 2009. Globalisation, international education and the marketing of TESOL: Student identity as a site of conflicting forces. PhD diss., Monash University.

Coverdale-Jones, T., and P. Rastall, eds. 2006. The Chinese Learner. Language, Culture and Curriculum 19, no. 1: 1-153.

Crystal, D. 2003. English as a global language (2nd edn). Cambridge: Cambridge University Press.

Ding, H. 2008. Living through ambiguity: The cross-cultural experience of Chinese students in London. PhD diss., University of London, Goldsmiths College.

Ding, H. 2009. East meets West: Chinese students making sense of their cultural identity in London. Changing English 16, no. 3: 313-321.

Dolby, N. 2005. Globalisation, identity, and nation: Australian and American undergraduates abroad. The Australian Educational Researcher 32, no. 1: 101-118. 
Edwards, V. and R. An. 2006. Meeting the Needs of Chinese Students in UK Higher Education.

http://www.ncll.org.uk/10_about/50_research/10_research_projects/chinesestuden $\underline{\text { ts } \_ \text {html. }}$.

Edwards, V., R. An, and D. Li. 2007. Uneven playing field or falling standards: Chinese students' competence in English. Race Ethnicity \& Education 10, no. 4: $387-400$.

Fuata'i, L. 2000. Stress and coping strategies: A study of international students in agricultural disciplines at the University of Reading - A Research Report. Reading: University of Reading.

Giddens, A. 1991. Modernity and self-identity: Self and society in the late modern age. Cambridge: Polity Press in association with Blackwell Publishing.

Graddol, D. 1997. The future of English. The British Council.

Hall, B. 2006. Social and cultural contexts in conversion to Christianity among Chinese American college students. Sociology of Religion 67, no. 2: 131-147.

Hsieh, M. 2006. Identity negotiation among female Chinese international students in second language higher education. College Student Journal 40, no. 4: 870-884.

Keeley, B. 2009. International migration: The human face of globalization. OECD. http://books.google.co.uk/books?id=wKozXPp3VqcC\&printsec=frontcover\&dq= migration:+the+human+face+of + globalization + Brian + Keeley\&source=bl\&ots $=$ Mgw2ZLedgG\&sig=svmS3pm4WVFhMzfGxdcYiTXXqh4\&hl=en\&ei=$\underline{\text { 2CNS_GFD5O7jAfXlpjXDA\&sa=X\&oi=book_result\&ct=result\&resnum }=2 \& v e}$ $\underline{\mathrm{d}=0 \mathrm{CA} 8 \mathrm{Q} 6 \mathrm{AEwAQ} \# \mathrm{v}=\text { onepage } \& \mathrm{q}=\& \mathrm{f}=\text { true }}$.

Li, D. 2001. Motivation, learner Strategies, and social networks in second language acquisition in Chinese research students. PhD diss., The University of Reading. 
Li, D. 2006. Motivation in second language acquisition in Chinese research students in the UK. Evaluation and Research in Education 19, no. 1: 38-58.

Li, D. 2007. Coping with linguistic challenges in UK Higher Education: The use of strategies by Chinese research students. Language Learning Journal 35, no. 2: 205-219.

Mendieta, E. 2003. Afterword Identities: Postcolonial and Global. In Identities: Race, class, gender, and nationality, ed. L. M. Alcoff and E. Mendieta, 407-416. Oxford: Blackwell Publishing.

Ng, K. H. 2002. Seeking the Christian Tutelage: Agency and culture in Chinese immigrants' conversion to Christianity. Sociology of Religion 63, no. 2: 195-214.

Patron, M. C. 2005. The re-negotiation of cultural identity of French academic sojourners during cross-cultural transition in Australia. In Stimulating the action as participants in participatory research, Vol. 3, ed. B. Bartlett, F. Bryer and R. Roebuck, 39-50. Nathan, Qld: Griffith University, School of Cognition, Language, and Special Education.

Philo, G. n. d. Cultural transfer: The impact of direct experience on evaluations of British and Chinese societies. Glasgow: Glasgow University Media Group. http://www.gla.ac.uk/centres/mediagroup/cultural\%20transfer.pdf.

Scollon, R., and S. W. Scollon. 1995. Intercultural Communication: A Discourse Approach. Oxford: Blackwell.

The British Council. 2008. China Market Introduction. http://www.britishcouncil.org/eumd-information-background-china.htm.

UKCOSA. 2004. Broadening Our Horizons: International Students in UK Universities and Colleges. London: UKCOSA. http://www.ukcosa.org.uk/survey/index.htm. 
Wang, Y., and F. Yang. 2006. More than Evangelical and ethnic: The ecological factor in Chinese conversion to Christianity in the United States. Sociology of Religion 67, no. 2: 179-192.

Yang, F. 1998. Chinese conversion to Evangelical Christianity: The importance of social and cultural contexts. Sociology of Religion 59, no. 3: 237-257.

Yang, F., and J. B. Tamney. 2006. Exploring mass conversion to Christianity among the Chinese: An introduction. Sociology of Religion 67, no. 2: 125-129.

Zhang, X. 2006. How religious organisations influence Chinese conversion to Evangelical Protestantism in the United States. Sociology of Religion 67, no. 2: 149-159. 